University of Wollongong

Research Online

Faculty of Engineering and Information

Faculty of Engineering and Information

Sciences - Papers: Part A

Sciences

$1-1-2013$

\title{
Removal of $\mathrm{N}$-nitrosamines by an aerobic membrane bioreactor
}

Kaushalya C. Wijekoon

University of Wollongong, kcw998@uowmail.edu.au

Takahiro Fujioka

University of Wollongong, tf385@uowmail.edu.au

James A. McDonald

University Of New South Wales

Stuart J. Khan

University Of New South Wales, s.khan@unsw.edu.au

Faisal I. Hai

University of Wollongong, faisal@uow.edu.au

See next page for additional authors

Follow this and additional works at: https://ro.uow.edu.au/eispapers

Part of the Engineering Commons, and the Science and Technology Studies Commons

Research Online is the open access institutional repository for the University of Wollongong. For further information contact the UOW Library: research-pubs@uow.edu.au 


\title{
Removal of $\mathrm{N}$-nitrosamines by an aerobic membrane bioreactor
}

\begin{abstract}
This study investigated the fate of eight $\mathrm{N}$-nitrosamines during membrane bioreactor (MBR) treatment. The results suggest that biodegradation is mainly responsible for the removal of $\mathrm{N}$-nitrosamines during MBR treatment. Other removal mechanisms were insignificant (e.g. adsorption to sludge) or not expected (e.g. photolysis and volatilization) given the experimental conditions and physicochemical properties of the $\mathrm{N}$-nitrosamines studied here. $\mathrm{N}$-nitrosamine removal efficiencies were from $24 \%$ to $94 \%$, depending on their molecular properties. High removal of $\mathrm{N}$-nitrosamines such as $\mathrm{N}$-nitrosodimethylamine and $\mathrm{N}$ nitrosodiethylamine could be explained by the presence of strong electron donating functional groups (EDG) in their structure. In contrast, N-nitrosomorpholine possessing the weak EDG morpholine was persistent to biodegradation. The removal efficiency of $\mathrm{N}$-nitrosomorpholine was $24 \%$ and was the lowest amongst all N-nitrosamines investigated in this study. (c) 2013.
\end{abstract}

\section{Keywords}

bioreactor, n, membrane, aerobic, nitrosamines, removal

Disciplines

Engineering | Science and Technology Studies

\section{Publication Details}

Wijekoon, K. C., Fujioka, T., McDonald, J. A., Khan, S. J., Hai, F. I., Price, W. E. \& Nghiem, L. D. (2013). Removal of N-nitrosamines by an aerobic membrane bioreactor. Bioresource Technology, 141 41-45.

\section{Authors}

Kaushalya C. Wijekoon, Takahiro Fujioka, James A. McDonald, Stuart J. Khan, Faisal I. Hai, William E. Price, and Long D. Nghiem 


\title{
Removal of N-nitrosamines by an aerobic membrane bioreactor
}

\author{
Revised Manuscript Submitted to
}

\section{Bioresource Technology}

January 2013

\author{
Kaushalya C. Wijekoon ${ }^{\text {a }}$, Takahiro Fujioka ${ }^{a}$, James McDonald ${ }^{b}$, Stuart J. Khan ${ }^{\text {b }}$, Faisal I. Hai ${ }^{\text {a }}$, \\ William E. Price ${ }^{c}$, and Long D. Nghiem ${ }^{\mathrm{a}, *}$ \\ ${ }^{a}$ Strategic Water Infrastructure Laboratory, School of Civil Mining and Environmental \\ Engineering, University of Wollongong, Wollongong, NSW 2522, Australia \\ ${ }^{b}$ Water Research Centre, The University of New South Wales, Sydney NSW 2052 Australia \\ ${ }^{\mathrm{c}}$ Strategic Water Infrastructure Laboratory, School of Chemistry \\ University of Wollongong, Wollongong, NSW 2522, Australia
}

* Corresponding author: Long Duc Nghiem, Email: longn@uow.edu.au; Ph +61 242214590

\begin{abstract}
This study investigated the fate of eight $\mathrm{N}$-nitrosamines during membrane bioreactor (MBR) treatment. The results suggest that biodegradation is mainly responsible for the removal of $\mathrm{N}$ nitrosamines during MBR treatment. Other removal mechanisms were insignificant (e.g. adsorption to sludge) or not expected (e.g. photolysis and volatilization) given the experimental conditions and physicochemical properties of the $\mathrm{N}$-nitrosamines studied here. $\mathrm{N}$-nitrosamine removal efficiencies were from 24 to $94 \%$, depending on their molecular properties. High removal of N-nitrosamines such as $\mathrm{N}$-nitrosodimethylamine and $\mathrm{N}$-nitrosodiethylamine could be explained by the presence of strong electron donating functional groups (EDG) in their structure. In contrast, Nnitrosomorpholine possessing the weak EDG morpholine was persistent to biodegradation. The removal efficiency of $\mathrm{N}$-nitrosomorpholine was $24 \%$ and was the lowest amongst all $\mathrm{N}$ nitrosamines investigated in this study.

Keywords: Membrane bioreactor (MBR), emerging trace organics, $N$-nitrosamines, biodegradation, removal mechanism.
\end{abstract}

\section{Introduction}

$\mathrm{N}$-nitrosamines are an emerging class of trace organic contaminants of significant health concern. They have been widely detected at trace level (in the order of a few nanograms per litre) in several environmental matrices including raw sewage, secondary treated effluent, and even drinking water 
(Mitch et al., 2003; Sedlak et al., 2005; Zhao et al., 2008). In particular, elevated concentrations of $\mathrm{N}$-nitrosamines have been reported in some wastewater (Mitch et al., 2003; Sedlak et al., 2005; Krauss et al., 2009). N-nitrosamines can originate from both industrial and domestic wastewater discharges. They can be generated as by-products from a range of industrial processes where amines are in contact with nitrite, nitrous acid and nitrogen oxides. Consequently N-nitrosamines frequently occur in wastewater discharges from industries such as tanneries, circuit board manufacturing, dye manufacturing, metal casting, rubber manufacturing, metal working and food processing (Sedlak and Kavanaugh, 2006). They may also be present in commercial products such as antifreezes, pesticides, detergents, processed meats, beverages, cigarette filters and cosmetics (Krauss et al., 2009). It is estimated that up to several hundred micrograms per litre of Nnitrosamines can be found in either untreated or treated industrial discharges from the above industries (Sedlak et al., 2005). In addition to industrial wastewater discharge, domestic wastewater also contributes to the N-nitrosamines load in wastewater (Sedlak et al., 2005). The occurrence of $\mathrm{N}$-nitrosamines in domestic wastewater can be attributed to the consumption of amines and nitrate rich food, cosmetics as well as household detergents. Furthermore, chloramination or chlorination of drinking water can also contribute to the elevated $\mathrm{N}$-nitrosamines concentration in domestic wastewater (Sedlak et al., 2005; Krauss et al., 2009).

Most N-nitrosamines have been classified as probable human carcinogens by the US environmental protection agency (Fujioka et al., 2012).Their carcinogenic effects have been detected even at several nanograms per litre (ng/L) (Sacher et al., 2008). Therefore, some N-nitrosamines have been regulated in both drinking water and recycling water guidelines. For example, the Australian Guidelines for Water Recycling sets the maximum value for N-nitrosodimethylamine (NDMA) and $\mathrm{N}$-nitrosomorpholine (NMOR) at 10 and $1 \mathrm{ng} / \mathrm{L}$, respectively (Fujioka et al., 2012). Other Nnitrosamines of concern to water authorities include $\mathrm{N}$-nitrosomethylethylamine (NMEA), Nnitrosopyrrolidine (NPYR), N-nitrosodiethylamine (NDEA), N-nitrosodipropylamine (NDPA), Nnitrosopiperidine (NPIP), and N-nitrosodi-n-butylamine (NDBA). Considering the probable adverse effects of the environmental occurrence of nitrosamines, their removal from wastewater is of paramount importance for the protection public health and the environment.

$\mathrm{N}$-nitrosamines appear to be biodegradable under both aerobic and anaerobic conditions. A number of studies have investigated their biodegradability in soils, groundwater, river bed sludge and isolated microbial cultures (Bradley et al., 2005; Drewes et al., 2006; Fournie et al., 2006; Zhou et al., 2009). Bradley et al., (2005) reported more than 54\% biodegradation of NDMA in soil from a wastewater reclamation facility under both oxic and anoxic conditions. Drewes et al., (2006) conducted a laboratory scale study of the removal of seven N-nitrosamines under conditions 
relevant to groundwater recharge operations. Half lives of these seven $\mathrm{N}$-nitrosamines were in the range from 1.3 to 7 days. However, Drewes et al., (2006) also noted some variation in the biodegradation rate of $\mathrm{N}$-nitrosamines and that complete removal of $\mathrm{N}$-nitrosamines would require the establishment of an adapted microbial community over several weeks or months. In a more recent study, Zhou et al., (2009) monitored the fate and transport of NDMA in groundwater being recharged with recycled water and reported that up to $80 \%$ of the recharged mass of NDMA could be biodegraded. The half life of NDMA under a recharge condition was 69.4 days (Zhou et al., 2009). Notably, only a few studies have reported the removal of N-nitrosamines from either industrial or domestic wastewaters by the conventional activated sludge (CAS) treatment process (Sedlak et al., 2005; Sacher et al., 2008; Krauss et al., 2009; Hatzinger et al., 2011). One of the most comprehensive studies to date, by Krauss et al., (2009), looked at the fate and removal of Nnitrosamines in 21 full scale convention wastewater treatment plants in Switzerland. They reported that the removal efficiencies from the aqueous phase by activated sludge treatment were generally above $40 \%$ for NMOR and over $60 \%$ for all other N-nitrosamines. The authors also noted the high variation in the removal efficiency of $\mathrm{N}$-nitrosamines amongst the 21 full scale plants investigated (Krauss et al., 2009). In comparison to the CAS treatment process, very little is known about the efficiency of membrane bioreactor (MBR) for the removal of N-nitrosamines during wastewater treatment. An MBR efficiently combines biodegradation and membrane filtration in a single step, compact process, and offers flexibility in operation and expansion as compared to CAS processes (Visvanathan et al., 2000). It is potentially more suitable for water recycling applications and the removal of trace organic compounds (Tadkaew et al., 2011; Boonyaroj et al., 2012; Navaratna et al., 2012). Hatzinger et al., (2011) recently reported a novel aerobic laboratory scale propane-fed MBR for the removal of NDMA from artificial groundwater. This appears to be the only study, which has investigated the removal of N-nitrosamines by MBR treatment to date. The authors reported over 99.9\% removal efficiency of NDMA. Given the unique configuration and operating condition of their propane-fed MBR, the results reported by Hatzinger et al., (2011) in case of groundwater may not be representative for a typical MBR used for wastewater treatment.

This study aims to increase our understanding of the removal of N-nitrosamines by MBR during wastewater treatment. The fate and removal efficiencies of eight $\mathrm{N}$-nitrosamines were systematically evaluated by a laboratory scale aerobic MBR by monitoring their concentrations in both the aqueous and sludge phase. Removal mechanisms of the selected N-nitrosamines were also elucidated by relating the removal efficiencies to their molecular structures. 


\section{Materials and methods}

\subsection{Membrane bioreactor system}

A laboratory scale MBR system was used in this study. The MBR system consisted of a $5 \mathrm{~L}$ glass reactor, water bath, an influent pump, a recirculation pump, an effluent pump and an external stainless steel membrane vessel that housed a ceramic membrane module. Tubular multi-channel ceramic membrane module (NGK, Japan) made of alumina with a nominal pore size of $1 \mu \mathrm{m}$ and an effective area of $0.09 \mathrm{~m}^{2}$ was used in this system. A water bath equipped with an immersion PID controlled heating unit (Julabo, Germany) was used to maintain a constant temperature in the MBR. Peristaltic pumps (Masterflex L/S, USA) were used for feeding, recirculation, and effluent extraction. The influent pump was continuously operated to provide wastewater to the reactor. The effluent pump was operated in $15 \mathrm{~min}$ on and $15 \mathrm{~min}$ off operating cycle to provide relaxation time to the membrane module. The influent pump flow rate was matched to that of the effluent pump to maintain a constant reactor volume. During the entire experiment, the MBR system was covered with aluminium foil to avoid any exposure to sunlight to prevent any possible photolysis of the Nnitrosamines. The system was operated at constant conditions. The hydraulic retention time (HRT), temperature, dissolved oxygen concentration (DO) and mixed liquor $\mathrm{pH}$ were $23.4 \mathrm{~h}, 30 \pm 0.1^{\circ} \mathrm{C}$, $2.68 \pm 0.47 \mathrm{mg} / \mathrm{L}$ and $7.27 \pm 0.18$, respectively. The mixed liquor suspended solid (MLSS) concentration in the reactor was maintained at $5.0 \pm 0.5 \mathrm{~g} / \mathrm{L}$ by regular withdrawal of the excess sludge every 4-5 days, resulting in a sludge retention time of approximately 175 days. The relatively low MLSS concentration and high HRT value used here were necessary to avoid membrane fouling and ensure a stable operating condition throughout the experiment.

\subsection{Target N-nitrosamine compounds}

Eight N-nitrosamines (namely NDMA, NMEA, NPYR, NPIP, NDEA, NMOR, NDPA and NDBA) were selected for investigation based on their widespread occurrence in wastewater and probable carcinogenic properties. These compounds have $\operatorname{low} \log D$ values (Table 1) and thus they can be classified as being hydrophilic. In addition, because they do not possess ionisable functional groups, these compounds can only exist in the aquatic environment as neutral species. All N-nitrosamines used in this study were of analytical grade and were purchased from Sigma-Aldrich (St Louis, MO, USA). A stock solution of all eight N-nitrosamines was prepared in pure methanol and kept at -18 ${ }^{\circ} \mathrm{C}$ in the dark. Their deuterated standards (N-nitrosodimethylamine-d6, Nnitrosomethylethylamine-d3, N-nitrosopyrrolidine-d8, N-nitrosopiperidine-d10, Nnitrosodiethylamine-d10, N-nitrosomorpholine-d8, N-nitrosodipropylamine-d14 and N-nitrosodi-nbutylamine-d9) purchased from CDN iso-topes (Pointe-Claire, Quebec, Canada) were used as 
surrogates. The surrogate stock solution was also prepared in methanol and kept at $-18{ }^{\circ} \mathrm{C}$ in the dark.

3. Table 1: Physicochemical properties of the selected N-nitrosamines (Fujioka et al., 2012).

\begin{tabular}{|c|c|c|c|c|c|c|c|c|}
\hline Compound & NDMA & NMEA & NPYR & NDEA & NPIP & NMOR & NDPA & NDBA \\
\hline Molecular weight $(\mathrm{g} / \mathrm{mol})$ & 74.05 & 88.06 & 100.06 & 102.08 & 114.08 & 116.06 & 130.11 & 158.14 \\
\hline Log D at pH 7 at $25^{\circ} \mathrm{C}$ & -0.5 & 0.01 & -0.09 & 0.52 & 0.44 & -0.59 & 1.54 & 2.54 \\
\hline $\begin{array}{c}\text { Henry's Law constant } \\
\text { at } 25^{\circ} \mathrm{C}\left(\mathrm{atm} \mathrm{m}^{3} / \mathrm{mol}\right)\end{array}$ & $1.2 \times 10^{-6}$ & $1.44 \times 10^{-6}$ & $1.99 \times 10^{-7}$ & $1.73 \times 10^{-6}$ & $2.81 \times 10^{-7}$ & $2.13 \times 10^{-10}$ & $3.46 \times 10^{-6}$ & $9.96 \times 10^{-6}$ \\
\hline
\end{tabular}

4.

\subsection{Synthetic wastewater}

Synthetic wastewater was used in this study to simulate medium strength domestic wastewater. This consisted of glucose (100 mg/L), peptone (100 mg/L), $\mathrm{KH}_{2} \mathrm{PO}_{4}(17.5 \mathrm{mg} / \mathrm{L}), \mathrm{MgSO}_{4}(17.5 \mathrm{mg} / \mathrm{L})$, $\mathrm{FeSO}_{4}(10 \mathrm{mg} / \mathrm{L})$, sodium acetate $(225 \mathrm{mg} / \mathrm{L})$ and urea $(35 \mathrm{mg} / \mathrm{L})$. A concentrated stock solution was prepared and kept at $4{ }^{\circ} \mathrm{C}$ in the dark. The synthetic wastewater was prepared each day by diluting the concentrated stock with Milli-Q water. A required volume of the N-nitrosamine stock solution was added to prepare a synthetic wastewater with approximately $250 \mathrm{ng} / \mathrm{L}$ of each $\mathrm{N}$ nitrosamine.

\subsection{Analytical methods}

Total organic carbon (TOC) and total nitrogen $(\mathrm{TN})$ were analysed using a TOC/TN- $\mathrm{V}_{\mathrm{CSH}}$ analyser (Shimadzu, Japan). All other basic parameters of the MBR process were analysed according to the standard methods for water and wastewater examination as reported in a previous study (Hai et al., 2011).

\subsection{N-nitrosamine analysis}

$\mathrm{N}$-nitrosamine concentrations were determined using solid phase extraction (SPE), gas chromatography (GC) and analysis by tandem mass spectrometry (MS-MS) with electron ionization (EI) using a method previously reported by (McDonald et al., 2012). Prior to the SPE procedure, the surrogate stock solution was added to the sample to obtain a concentration of $50 \mathrm{ng} / \mathrm{L}$ of each internal standard. The samples were then extracted using the Supelclean ${ }^{\mathrm{TM}}$ Coconut Charcoal SPE cartridges ( 2 g/mL, supplied by Supelco, St Louis, MO, USA). Extracted compounds were eluted from the cartridges using dichloromethane $(4 \times 3 \mathrm{~mL})$ and concentrated to $1 \mathrm{~mL}$ under a slight stream of high purity nitrogen in a Turbovap LV evaporation system (Caliper Life Sciences, Hopkinton, MA, USA). A volume of $100 \mu \mathrm{L}$ of toluene was added to the eluted sample to minimize compound evaporative loss. Finally, concentrated samples were transferred to $2 \mathrm{~mL} \mathrm{GC}$ vials for 
instrumental analysis. Samples were analysed on an Agilent 7890A GC coupled with an Agilent 7000B triple quadrupole tandem mass spectrometer (MS/MS). The quantitative detection limit of this method was less than $4 \mathrm{ng} / \mathrm{L}$ for all $\mathrm{N}$-nitrosamines investigated in this study.

N-Nitrosamines were also extracted from sludge using a solvent extraction method. First, the sludge sample was centrifuged and the solid pellet was freeze dried for 4 hour using an Alpha 1-2 LDplus Freeze Dryer (Christ GmbH, Germany). The dried sludge was ground to powder and $0.5 \mathrm{~g}$ of sludge was transferred into a glass test tube. Methanol $(5 \mathrm{~mL})$ was added to the test tube, thoroughly mixed using a vortex mixer for $3 \mathrm{~min}$ and ultrasonicated for $10 \mathrm{~min}$ at $40{ }^{\circ} \mathrm{C}$. The sample was centrifuged at $3750 \mathrm{rpm}$ for $10 \mathrm{~min}$ (Alleegra X-12R, Beckman Coulter, USA) and the supernatant was collected in a glass beaker for further analysis. Dichloromethane $(5 \mathrm{~mL})$ and methanol $(5 \mathrm{~mL})$ were added to the remaining sludge. The mixing, ultrasonic extraction and centrifuge procedure was repeated to obtain another supernatant. Both supernatants were then mixed together, added Milli-Q water up to $50 \mathrm{~mL}$ and residue methanol and dichloromethane were purged using nitrogen gas. Finally, Milli-Q water was added to obtain a $200 \mathrm{~mL}$ aqueous sample. This sample was then analysed using the analytical method described above. The mass balance of each N-nitrosamine was calculated based on the concentration in the feed, effluent, and sludge phase as well as the permeate flow and the rate sludge extraction to determine their fate and transport during MBR treatment.

\section{Results and discussion}

\subsection{Biological performance of the MBR system}

Prior to the main experimental phase of the study, the MBR system was acclimatised for four months under constant operating conditions. Synthetic feed solution simulating domestic wastewater was used to assure a consistent feed composition. Throughout this acclimatisation period, the effluent quality was stable. N-nitrosamines were introduced to the feed solution and the MBR system continued to operate under the same conditions to maintain operational stability. TOC and TN concentrations of the feed solution were $167.3 \pm 8.0 \mathrm{mg} / \mathrm{L}$ and $29.8 \pm 0.7 \mathrm{mg} / \mathrm{L}$ respectively. Key operational parameters including DO and $\mathrm{pH}$ were continuously examined to affirm the biological stability of the MBR. As expected, the performance of the MBR system with respect to a range of basic performance parameters, such as TOC removal, TN removal, permeate turbidity, DO and the ratio of MLVSS/MLSS were stable throughout this study. Both TOC and TN removals were stable at $88 \pm 0.8 \%$ and $48.3 \pm 4 \%$, respectively. The low TN removal efficiency observed here can be attributed to the absence of an anoxic chamber in our lab scale MBR which is necessary for an effective denitrification process. Turbidity of the MBR permeate was always below 0.7 NTU with an average of $0.46 \pm 0.12$ NTU. The MLSS concentration in the reactor was 
maintained at $5.0 \pm 0.5 \mathrm{~g} / \mathrm{L}$ by withdrawing excess sludge every 4-5 days, resulting in a theoretical sludge retention time of approximately 175 days. The MLVSS/MLSS ratio of the sludge was constant at $0.79 \pm 0.02$ throughout this study. In addition, MBR system was operated at a transmembrane pressure below $90 \mathrm{kPa}$ and no abnormal variation in transmembrane pressure was observed throughout the entire study.

\subsection{Fate and transport of $N$-nitrosamines during aerobic MBR treatment}

Fate and transport of the eight $\mathrm{N}$-nitrosamines investigated in this study by MBR treatment are shown in Figure 1. Relatively constant concentrations of most N-nitrosamines in the aqueous and solid (sludge) phase can be observed (Figure 1). However, some variations were noted in the removal of NPYR and NPIP. Similar temporal variations in the removal rate of NDMA and NMOR by conventional wastewater treatment plants have also been reported in the literature (Sedlak et al., 2005; Krauss et al., 2009). Given the relatively stable operating conditions of the current study, the small temporal variations described here could possibly be attributed to the sensitivity of $\mathrm{N}$ nitrosamines removal in wastewater treatment. 

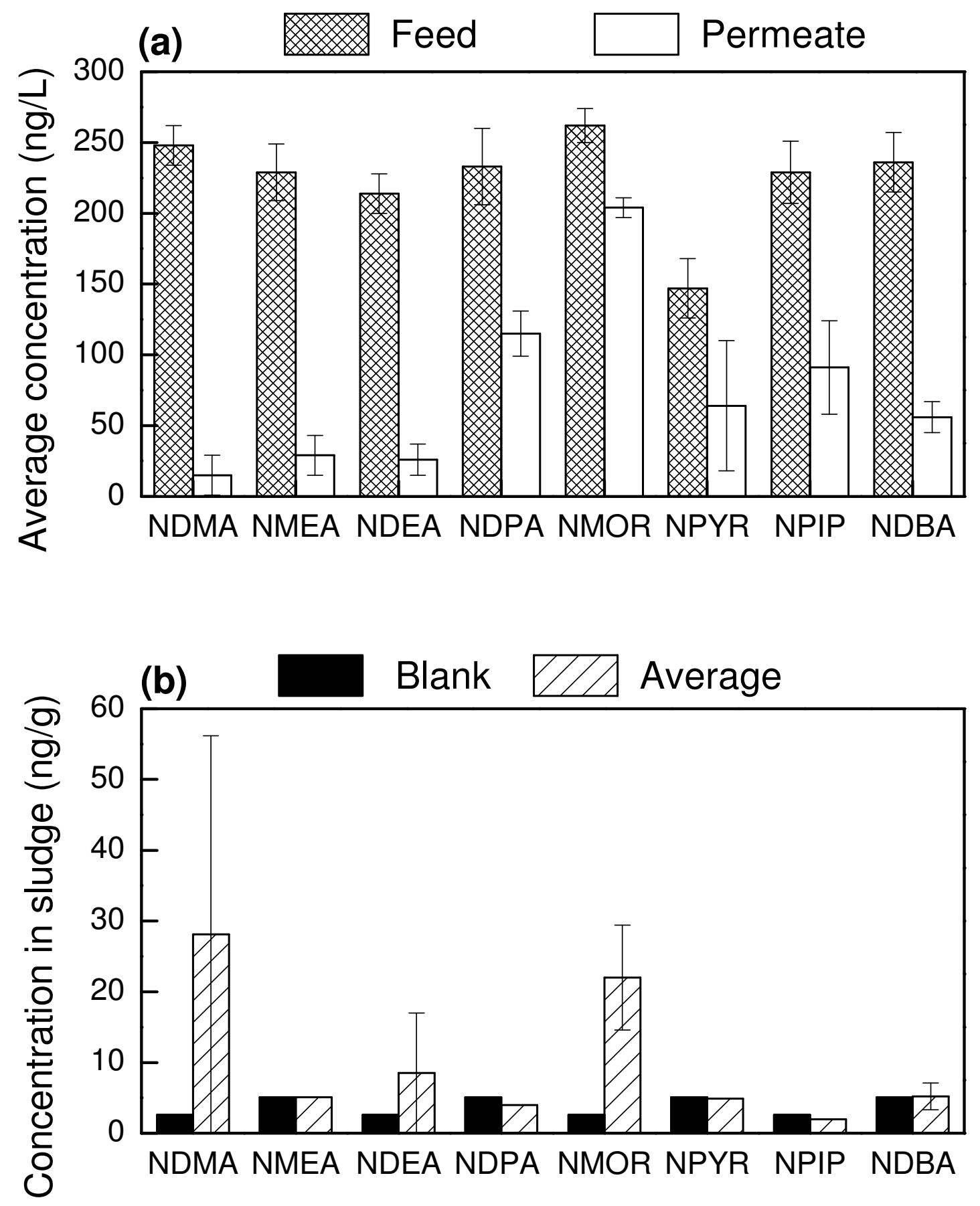

\section{Figure 1}

Fate and transport of trace organic contaminants during MBR treatment can be governed by biodegradation, adsorption, photolysis and volatilization. UV oxidation or photolysis can be an important removal mechanism of N-nitrosamines (Mitch et al., 2003). However, in this study, as described in section 2.1, the MBR system was covered with aluminium foil to prevent any accidental photolysis of N-nitrosamines. All eight N-nitrosamines selected for this investigation have very low Henry's Law constants (Table 1). As a result, their volatilization due to aeration is expected to be negligible. $\mathrm{N}$-nitrosamines concentration in solid phase was insignificant due to their hydrophilic nature which is reflected by their $\operatorname{low} \log D$ values (Table 1 ). In addition to its relatively 
low removal from the aqueous phase, NMOR was detected in the solid phase at approximately 22 ng/g, which was slightly higher than most other N-nitrosamines. This can be attributed to the persistence of NMOR to biodegradation, which will be discussed further in the next section. A significant variation in the concentration of NDMA in the sludge phase was also observed, however this is likely due to an error during sample preparation and analysis. Overall, it is clear that biodegradation (or transformation) governed the fate of all eight $\mathrm{N}$-nitrosamines selected in this study during MBR treatment (Figure 2).

$\square$ Biodegradation/Transformation Sludge Permeate

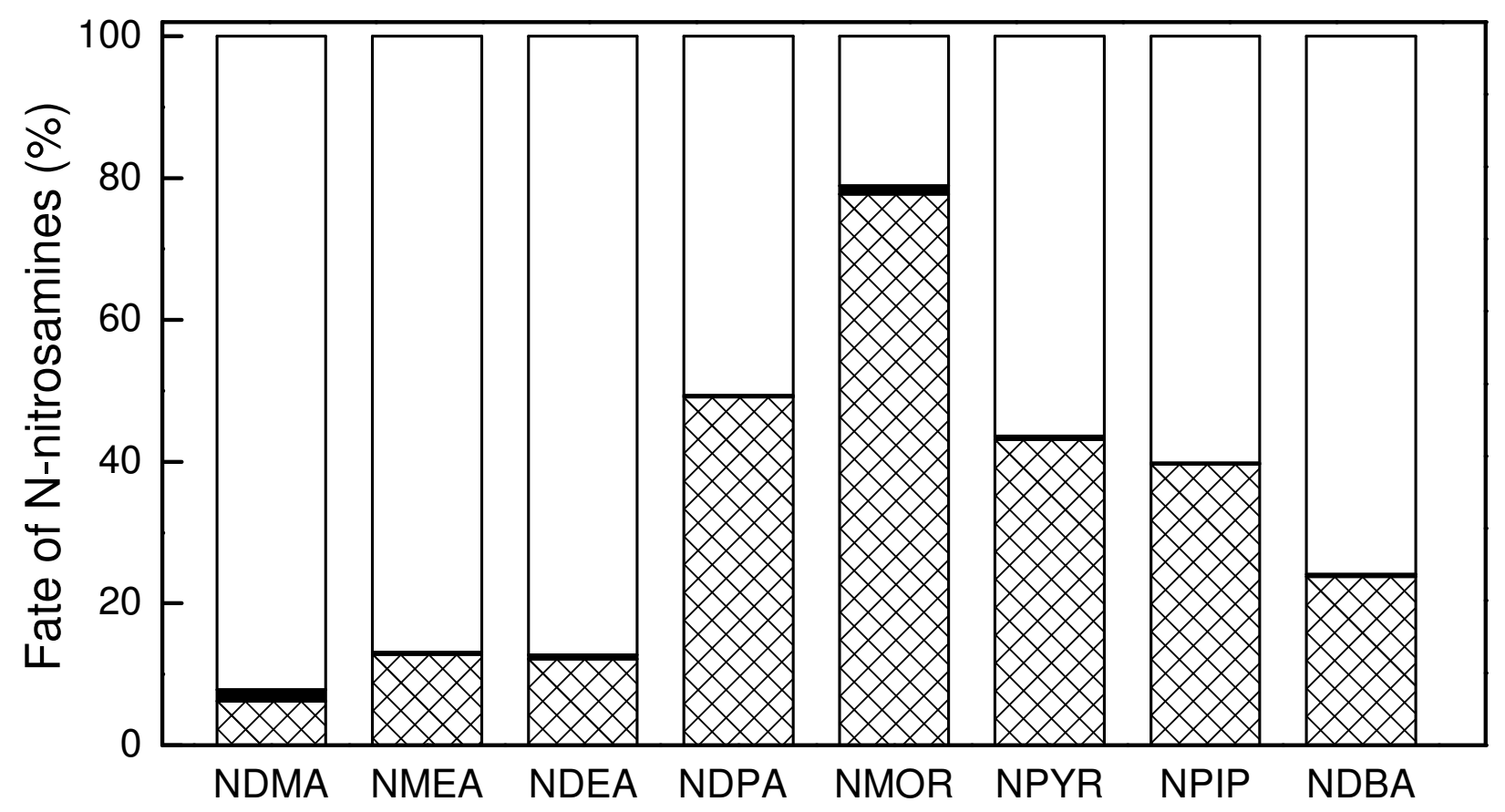

4.

\section{Figure 2}

\subsection{Removal mechanisms of $\mathrm{N}$-nitrosamines during MBR treatment}

The removal efficiencies of NDMA (94\%), NMEA (87\%), NDEA (88\%), NDPA (51\%), NDBA (76\%), NPYR (58\%), NPIP (65\%), and NMOR (24\%) obtained in this study are comparable with their removal efficiencies by the CAS treatment process previously reported by Krauss et al., (2009) and Sedlak et al., (2005). In a comprehensive survey of 21 full scale conventional wastewater treatment facilities, Krauss et al., (2009) reported that the removal efficiencies of most $\mathrm{N}$ nitrosamines were generally above $60 \%$. They also singled out NMOR as a persistent compound amongst the seven $\mathrm{N}$-nitrosamines investigated in their study. However, their reported removal efficiency of NMOR (40\%) was higher than that obtained in this study (24\%).

As discussed in section 3.2, the removal of N-nitrosamines reported here can be attributed mainly to their biodegradability. It appears that biodegradation of $\mathrm{N}$-nitrosamines can be qualitatively 
predicted based on their molecular structure according to the framework proposed recently by Tadkaew et al., (2011). Indeed, the removal efficiencies of $\mathrm{N}$-nitrosamines reported here are, in general, in the order of acyclic (NDMA, NMEA, NDEA, NDPA, and NDBA) > alicyclic (NPYR and NPIP) > morpholine (NMOR). According to Knackmuss (1996), the initial electrophilic attack by oxygenases of aerobic bacteria is often a rate-limiting step and the first of a chain of reactions responsible for the biodegradation of many organic compounds. As a result, the presence of electron withdrawing functional groups (EWGs) generates an electron deficiency and thus renders the compounds less susceptible to oxidative catabolism. Electron donating functional groups (EDGs), on the other hand, render the molecules more prone to electrophilic attack by oxygenases of aerobic bacteria. Thus, biodegradation of trace organic compounds can be predicted based on the occurrence of EWGs or EDGs in their molecular structure (Tadkaew et al., 2011). Organic compounds with strong EWGs (such as halogens and nitro) are more likely to be persistent to biodegradation. In contrast, organic compounds with strong EDGs (such as hydroxyl and alkyl) are readily amendable to biodegradation. The molecular architecture of $\mathrm{N}$-nitrosamines consists of both EWG (i.e. nitroso) and EDG (i.e. amine or morpholine). Nitroso is a strong EWG while amine is a strong EDG (Carey and Giuliano, 2010). Thus, all N-nitrosamines except NMOR are quite amendable to MBR treatment despite the presence of the nitroso functional group. In addition, their removal efficiencies can be explained to some extent based on the strength of their electron donating functional groups. Electron donating capacity of amines is influenced by the alkyl chains by the inductive effect (Carey and Giuliano, 2010). The inductive effect is weakened as the length of the aliphatic chain increases (Carey and Giuliano, 2010). Similarly, acyclic alkyl amines have a stronger electron donating capacity than that of alicyclic alkyl amines (Carey and Giuliano, 2010). As a result, NDMA with two methyl functional groups exhibited the highest removal efficiency amongst all N-nitrosamines investigated here. Furthermore, in general, acyclic N-nitrosamines were better removed by MBR treatment than their aliphatic counterparts. The oxygen atom in the morpholine functional group substantially reduces its electron donating capacity. As a result, NMOR removal is dominated by the strong EWG nitroso. In good agreement to the qualitative framework proposed by Tadkaew et al., (2011), NMOR is persistent to biodegradation and this compound exhibited the lowest removal efficiency by MBR treatment amongst all eight Nnitrosamines studied here. Better removal of acyclic N-nitrosamines in comparison to their alicyclic counterparts is also consistent with their potential biodegradation pathways given in the Biocatalysis/Biodegradation Pathway Database of the University of Minnesota (https://umbbd.ethz.ch/predict/). The aerobic biodegradation of acyclic N-nitrosamines (NMEA, NDEA and NDPA) is likely to be initiated by converting the aliphatic backbone to an alcohol. In fact, demethylation has been identified as a key metabolism pathway of NDMA in mammalian cells 
(Fournie et al., 2006). On the other hand, the aerobic biodegradation of NMOR can possibly be initiated by converting the unsubstituted cyclic ether to hydroxyl cyclic ether, which has a much higher energy barrier than the demethylation process. This difference in the potential aerobic biodegradation pathways could possibly explain for the reported lower removal of NMOR compared to the other acyclic N-nitrosamines. In addition to the effect of molecular structure on nitrosamines removal, the microbial population of the biomass might also influence the removal of $\mathrm{N}$-nitrosamines. Nevertheless, detailed analysis of the microbial population diversity of the biomass is beyond the scope of the current study.

\section{Conclusion}

Biodegradation is the predominant removal mechanism for N-nitrosamines. Adsorption to sludge was negligible while photolysis and volatilization were not expected to occur. N-nitrosamine removal efficiencies were dependent on their molecular structure, and ranged from 24 to $94 \%$. The results could be explained by the presence of EWGs and EDGs (and their relative strength) in the $\mathrm{N}$-nitrosamine molecules. N-nitrosamines possessing strong EDGs such as dimethyl-amine and diethyl-amine (e.g. NDMA and NDEA) are readily biodegradable during MBR treatment. By contrast, NMOR which has the weak EDG morpholine was persistent to biodegradation and its removal efficiency by MBR treatment was correspondingly the lowest.

\section{Acknowledgement}

The first author (Kaushalya C. Wijekoon) would like to thank the University of Wollongong for the PhD scholarship support.

\section{References}

[1] Boonyaroj, V., C. Chiemchaisri, W. Chiemchaisri, S. Theepharaksapan and K. Yamamoto (2012). Toxic organic micro-pollutants removal mechanisms in long-term operated membrane bioreactor treating municipal solid waste leachate. Bioresource Technology 113(0): 174-180.

[2] Bradley, P. M., S. A. Carr, R. B. Baird and F. H. Chapelle (2005). Biodegradation of Nnitrosodimethylamine in Soil from a Water Reclamation Facility. Bioremediation Journal 9(2): 115-120.

[3] Carey, F. and R. M. Giuliano (2010). Organic Chemistry. New York:, McGraw-Hill Science Engineering. 
[4] Drewes, J. E., C. Hoppe and T. Jennings (2006). Fate and Transport of N-Nitrosamines Under Conditions Simulating Full-Scale Groundwater Recharge Operations. Water Environment Research 78(13): 2466-2473.

[5] Fournie, D., J. Hawari, S. H. Streger, K. McClay and P. B. Hatzinger (2006). Biotransformation of N-Nitrosodimethylamine by Pseudomonas mendocina KR1. Applied Environmental Microbiology 72(10): 6693-6698.

[6] Fujioka, T., S. J. Khan, Y. Poussade, J. E. Drewes and L. D. Nghiem (2012). N-nitrosamine removal by reverse osmosis for indirect potable water reuse - A critical review based on observations from laboratory-, pilot- and full-scale studies. Separation and Purification Technology 98(0): 503-515.

[7] Hai, F. I., K. Tessmer, L. N. Nguyen, J. Kang, W. E. Price and L. D. Nghiem (2011). Removal of micropollutants by membrane bioreactor under temperature variation. Journal of Membrane Science 383(1-2): 144-151.

[8] Hatzinger, P. B., C. Condee, K. R. McClay and A. Paul Togna (2011). Aerobic treatment of Nnitrosodimethylamine in a propane-fed membrane bioreactor. Water Research 45(1): 254-262.

[9] Knackmuss, H.-J. (1996). Basic knowledge and perspectives of bioelimination of xenobiotic compounds. Journal of Biotechnology 51(3): 287-295.

[10] Krauss, M., P. Longrée, F. Dorusch, C. Ort and J. Hollender (2009). Occurrence and removal of N-nitrosamines in wastewater treatment plants. Water Research 43(17): 4381-4391.

[11] McDonald, J. A., N. B. Harden, L. D. Nghiem and S. J. Khan (2012). Analysis of Nnitrosamines in water by isotope dilution gas chromatography-electron ionisation tandem mass spectrometry. Talanta 99(0): 146-154.

[12] Mitch, W. A., J. O. Sharp, R. R. Trussell, R. L. Valentine, L. Alvarez-Cohen and D. L. Sedlak (2003). N-Nitrosodimethylamine (NDMA) as a drinking water contaminant: A review.

Environemtanl Engineering Science 20(5): 389-404.

[13] Navaratna, D., J. Elliman, A. Cooper, L. Shu, K. Baskaran and V. Jegatheesan (2012). Impact of herbicide Ametryn on microbial communities in mixed liquor of a membrane bioreactor (MBR). Bioresource Technology 113(0): 181-190.

[14] Sacher, F., C. K. Schmidt, C. C. Lee and U. V. Gunten (2008). Stratergies for minimizing nitrosamine formation during disinfection, AWWA Research Foundation. 
[15] Sedlak, D. L., R. A. Deeb, E. L. Hawley, W. A. Mitch, T. D. Durbin, S. Mowbray and S. Carr (2005). Sources and Fate of Nitrosodimethylamine and its Precursors in Municipal Wastewater Treatment Plants. Water Environment Research 77(1): 32-39.

[16] Sedlak, D. L. and M. Kavanaugh (2006). Removal and destruction of NDMA and NDMA precursors during wastewater treatment. Alexandria, VA, WaterReuse Foundation.

[17] Tadkaew, N., F. I. Hai, J. A. McDonald, S. J. Khan and L. D. Nghiem (2011). Removal of trace organics by MBR treatment: The role of molecular properties. Water Research 45(8): 24392451.

[18] Visvanathan, C., R. B. Aim and K. Parameshwaran (2000). Membrane Separation Bioreactors for Wastewater Treatment. Critical Reviews in Environmental Science and Technology 30(1): 1-48.

[19] Zhao, Y.-Y., J. M. Boyd, M. Woodbeck, R. C. Andrews, F. Qin, S. E. Hrudey and X.-F. Li (2008). Formation of N-Nitrosamines from Eleven Disinfection Treatments of Seven Different Surface Waters. Environmental Science \& Technology 42(13): 4857-4862.

[20] Zhou, Q., S. McCraven, J. Garcia, M. Gasca, T. A. Johnson and W. E. Motzer (2009). Field evidence of biodegradation of N-Nitrosodimethylamine (NDMA) in groundwater with incidental and active recycled water recharge. Water Research 43(3): 793-805.

\section{LIST OF FIGURES CAPTIONS}

Figure 1: (a) Average concentrations of selected N-nitrosamines in feed and permeate streams of MBR system; error bars represent the standard deviation of ten consecutive measurements (b) Average concentration of selected N-nitrosamines in sludge over the experimental period; error bars represent the standard deviation of four consecutive measurements. MBR operating temperature, dissolved oxygen, $\mathrm{pH}$, MLSS, HRT and SRT were maintained at $30{ }^{\circ} \mathrm{C}, 2.68 \pm 0.47 \mathrm{mg} / \mathrm{L}, 7.3 \pm 0.2$ and $5.0 \pm 0.5 \mathrm{mg} / \mathrm{L}, 24 \mathrm{~h}$ and 175 days respectively.

Figure 2: Overall fate of N-nitrosamines during MBR treatment. 